\title{
Hematological changes in pregnancy induced hypertension in their third trimester at Jhalawar Medical College, Jhalawar, India
}

\author{
Neelam Jhajharia*, Madhureema Verma
}

Department of Obstetrics and Gynaecology, Jhalawar Medical College, Jhalawar, Rajasthan, India

Received: 28 June 2019

Revised: 24 July 2019

Accepted: 29 July 2019

*Correspondence:

Dr. Neelam Jhajharia,

E-mail: neelamjhajharia02@gmail.com

Copyright: (C) the author(s), publisher and licensee Medip Academy. This is an open-access article distributed under the terms of the Creative Commons Attribution Non-Commercial License, which permits unrestricted non-commercial use, distribution, and reproduction in any medium, provided the original work is properly cited.

\begin{abstract}
Background: Pregnancy induced hypertension $(\mathrm{PIH})$ is one of the most common and potential life-threatening complications of pregnancy. This study is aimed to investigate and correlate the hemoglobin, haematocrit, white blood cell count, lymphocytes and platelets in PIH patients in their third trimester.

Method: Total 126 subjects were studied out of them 63 patients (case) and 63 healthy pregnant women (control) visiting the Obstetrics and Gynaecology department Jhalawar Medical College, Jhalawar were registered in the study and followed during their pregnancy. Two millilitre of blood sample was drawn aseptically using the $5 \mathrm{ml}$ syringe from the median ante cubital vein of all the cases and control participants into EDTA-anticoagulated tubes. Haematological parameter calculated by using Sysmex XN-9100M Automated Haematology System.

Results: The mean hemoglobin level of the case group $(8.8206 \pm 2.53779)$ was significantly lower than that of the control group $(9.7289 \pm 2.47033)(\mathrm{p}<0.05)$. The mean platelet count of the case group $(131.4937 \pm 62.05999)$ was significantly lower than that of the control group $(324.9683 \pm 230.78764)(\mathrm{p}<0.05)$. The mean lymphocytes level of case group (1.2510 \pm 0.56369$)$ was significantly lower than that of the control group $(1.9295 \pm 1.4150)(p<0.05)$. The mean WBC level of case group $(36.3467 \pm 119.90635)$ was significantly high than control group (11.5260 \pm 4.83059$)$ $(\mathrm{p}<0.05)$. The mean haematocrit level of case group $(32.6851 \pm 7.29789)$ was significantly high than control group $(30.0424 \pm 23.38116)(\mathrm{p}<0.05)$.

Conclusion: The mean hemoglobin, mean platelets and mean lymphocytes are lower in PIH patients. The mean WBC and haematocrit are higher in PIH patient.
\end{abstract}

Keywords: Hemoglobin, Haematocrit, Hypertension, Platelets, Pregnancy, Lymphocyte, White Blood Cell

\section{INTRODUCTION}

Pregnancy induced hypertension $(\mathrm{PIH})$ is the one of the most common and serious medical disorder of pregnancy which contributing significantly to both maternal and neonatal morbidity and mortality. ${ }^{1}$ PIH affecting approximately $5-7 \%$ of pregnancies and in India the incidence of $\mathrm{PIH}$ is from $5 \%$ to $15 \%$. $^{2}$ The Hypertensive disorders complicating pregnancy form one of the deadly triads of maternal death along with sepsis and haemorrhage. PIH has been divided into four categories as recommended by the National High Blood Pressure Education Program Working Group on High Blood Pressure in Pregnancy. ${ }^{3}$ Gestational hypertension, Preeclampsia and Eclampsia, Chronic hypertension of any aetiology and preeclampsia superimposed on chronic hypertension. Preeclampsia is defined as BP>140/90 or higher, measured on at least two occasions, $2 \mathrm{~h}$ apart after 20 weeks of gestation and proteinuria $(300 \mathrm{mg}$ or more of urinary protein for $24 \mathrm{hrs}$ or $100 \mathrm{mg} / \mathrm{dl}$ or more in at least two random urine specimens collected 6 or more hours apart). ${ }^{4}$ Severe preeclampsia when Bp of $160 / 110$ or 
higher measured on two occasions at least $6 \mathrm{~h}$ apart and Proteinuria of $>5 \mathrm{~g}$ in $24 \mathrm{~h}$ (or proteinuria equal to or greater than +3 as measured by urinary reagent strips in at least two random specimens collected 4hapart)or oliguria $<400 \mathrm{ml}$ in $24 \mathrm{~h}$, or cerebral or visual disturbances. Hypertension, proteinuria, excessive weight gain and oedema are classic clinical manifestations of preeclampsia. ${ }^{5}$ Other features include throm bocytopenia, anaemia, haemoconcentration, hyperuricemia, abnormal liver function tests. ${ }^{6,7}$ PIH may present with diverse Haematological features, varying from normal laboratory tests to severe thrombocytopenia (due to platelet activation and consumption), and anaemia. Preeclampsia represents a state of hemo concentration and increased hematocrit levels. A fall in repeat hematocrit values may denote clinicalimprovement. ${ }^{8}$ This study is aimed to investigate the hemoglobin, hematocrit, WBC (white blood cell), lymphocytes and platelet counts in $\mathrm{PIH}$ patients in their third trimester.

\section{METHODS}

\section{Study area}

This present study was carried out at the Obstetrics and Gynaecology department of Jhalawar medical college Jhalawar district, Rajasthan, India.

\section{Study Subjects}

Total of 126 subjects were studied. 63 patients (case group) and 63 healthy pregnant women (control group). The subjects for this case control study included 63 consecutively-recruited pregnancy induced hypertensive pregnant women visiting the Obstetrics and Gynaecology department Jhalawar medical college Jhalawar, Rajasthan, India. The women included in this study were taken from outpatient department and from admission wards after 20 weeks of pregnancies. On development of pre-eclampsia and fulfilment of selection criteria they were enrolled in the study group. The women representing the control group were chosen from the women who fulfilled the inclusion criteria but did not develop pre-eclampsia. They were normotensive, with no proteinuria. The women were informed about the procedure and a verbal informed consent was taken before taking the sample. While evaluating the results of the study, relevant clinical data was collected from every patient, which included detailed history, general, systemic and obstetric examinations, baseline investigations including ultrasonography were performed. Blood pressure was measured in the right arm in semirecumbent position with the arm at the level of heart. The blood sample was taken from the ante- cubital vein. Two milliliter of blood sample was drawn aseptically using the $5 \mathrm{ml}$ syringe from the median ante cubital vein of all the case and control participants into EDTA-anticoagulated tubes. Haemoglobin, haematocrit, platelets, WBC and lymphocytes were counted using Sysmex XN-9100' Automated Haematology System. The statistics used to analyze the data was mean, standard deviation and student t- test. For all analytical teststhe level of significance was $\mathrm{p}<0.05$. Ethical clearance for the study was taken from the Ethical Committee, Jhalawar medical college \& hospital.

\section{Inclusion criteria}

- Patients having pre-eclampsia. As defined and classified by standard criteria of the American College of Obstetricians and Gynecologists

- Non-smoker Primigravida with Singleton pregnancy

- Age between 20 and 36 years

- Gestation age:After 20weeks onwards (calculated from the first day of last menstrual period).

\section{Exclusion criteria}

- Multiple pregnancies

- Previous history of hypertension and proteinuria before conception or before 20 weeks of gestation

- History of systemic illnesses like diabetes mellitus, renal disease, liver diseases

- Eclampsia

- History of hypertension without proteinuria

- Women with history of recent blood transfusion.

\section{RESULTS}

Total of 126 subjects were studied. In which 63 patients (case group) and 63 healthy pregnant women (control group). The mean age of cases was (27.5079 \pm 3.18197$)$ years and controls was $(28.3651 \pm 2.74333)$ years with $\mathrm{p}$ value $(0.108)$. There is no significant difference in age between cases and control ( $p>0.05)$ (Table 1).

Table 1: Mean age distribution of case and control group.

\begin{tabular}{|llll|}
\hline Variable & $\begin{array}{l}\text { Case } \\
(\mathrm{n}=63) \\
\text { Mean } \pm \text { SD }\end{array}$ & $\begin{array}{l}\text { Control } \\
(\mathrm{n}=63) \\
\text { Mean } \pm \text { SD }\end{array}$ & $\begin{array}{l}\text { P } \\
\text { value }\end{array}$ \\
\hline Age (year) & $27.51 \pm 3.2$ & $28.36 \pm 2.7$ & 0.108 \\
\hline
\end{tabular}

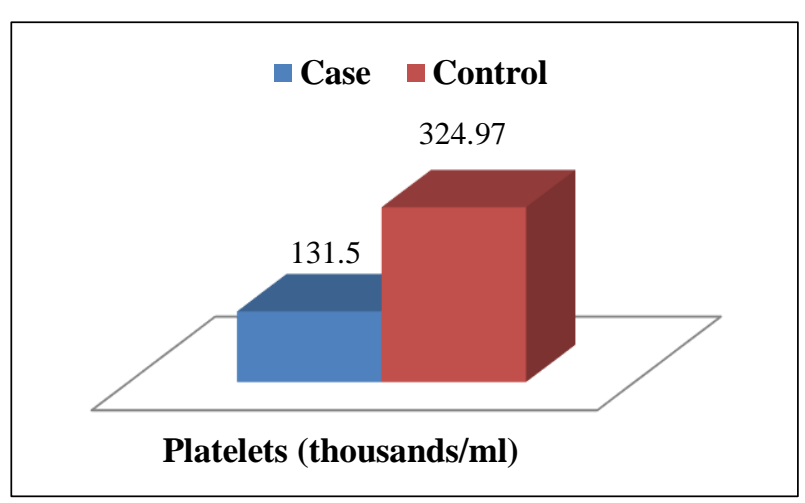

Figure 1: Mean value of platelets in case and control group. 
The mean platelet count of the case group $(131.4937 \pm 62.05999)$ thousand/ml which was significantly lower than that of the control group $(324.9683 \pm 230.78764)$ thousand $/ \mathrm{ml}(\mathrm{p}<0.0001)$. (Figure $1)$.

The mean haemoglobin level of case group $(8.8206 \pm 2.53779) \mathrm{gm} / \mathrm{dl}$ was significantly lower than the control group $(9.7289 \pm 2.47033) \mathrm{gm} / \mathrm{dl}(\mathrm{p}<0.05)$. The

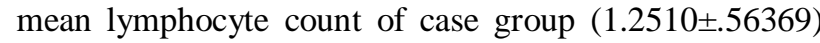
thousand/ml was significantly lower than that of the control group $(1.9296 \pm 1.41505)$ thousand $/ \mathrm{ml}(\mathrm{p}<0.05)$. (Figure 2).

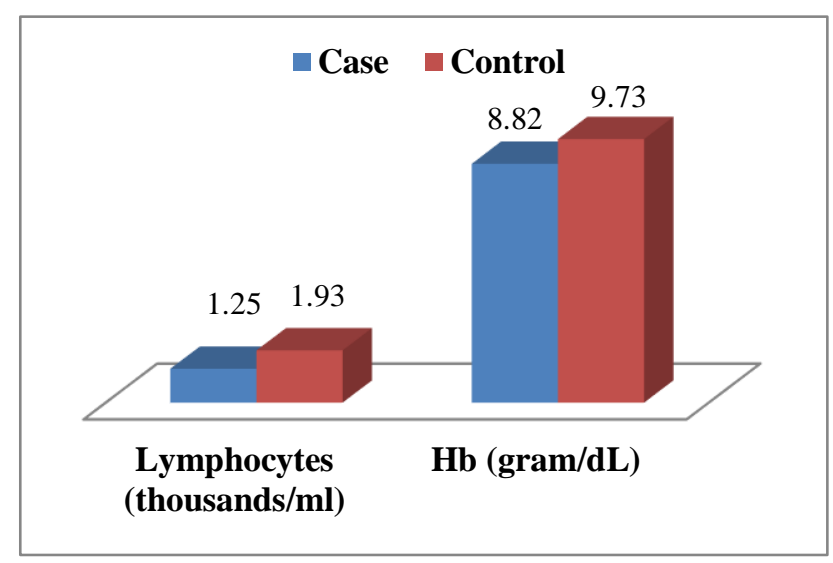

Figure 2: Mean value of Lymphocytes and $\mathrm{Hb}$ in case and control group.

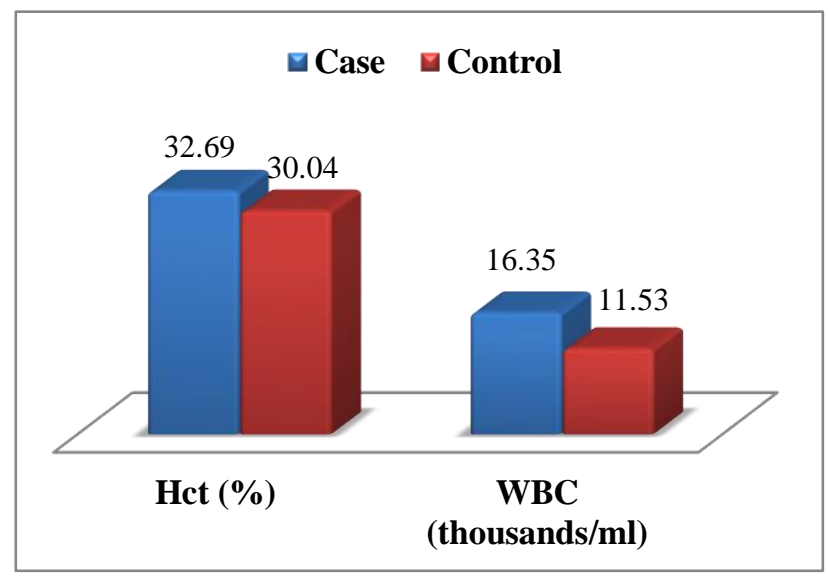

Figure 3: Mean value of haematocrit and $\mathrm{WBC}$ in case and control group.

The mean WBC of cases group (16.3467 \pm 1.99906$)$ thousand/ml which are higher than and control group $(11.5260 \pm 4.83059)$ thousand/ml $(\mathrm{p}<0.05)$. There was significant difference in WBC counts of case and control group. The mean haematocrit of case group (32.6851 \pm 7.29789$) \%$ which was significantly higher than control group $(30.0424 \pm 23.38116) \%(\mathrm{p}<0.05)$. It shows patient with preeclampsia had higher haematocrit than non-preeclampsia patient (Figure 3).

\section{DISCUSSION}

Pre-eclampsia is one of the leading causes of maternal and fetal morbidity and mortality. After active research for many years the etiology of PIH remains unclear. Recent evidence suggests that there may be several underlying causes or predispositions leading to endothelial dysfunction and causing the signs of hypertension, proteinuria and edema findings that allmaking the diagnosis of the syndrome of preeclampsia. ${ }^{9}$ Present study was undertaken to evaluate hematological parameters in preeclampsia.

In our study there was a significant reduction in the platelet count in the pre-eclampsia as compared to control group (Figure 1). It has also been reported that the mean value of platelet counts was significantly decreased in the pre-eclamptic patients than normotensive pregnant women. In study of Imteyaz Ganai (MD) et al. total of 200 women (primigravida's) were included and show that in preeclamptic women platelet count was less and bleeding time was more than normotensive controls ( $p$ $<0.001$ ). Our finding is indicating that low platelet count is more apparent during $3^{\text {rd }}$ trimester of pregnancy. The variation in platelet count among pregnant women with PIH may be due to an increased consumption with reduced life span and increased aggregation by increased levels of thromboxane A2 at placental circulation. ${ }^{10}$ Thromboxane A2 promotes vasospasm, induces supplementary platelet aggregation and endothelial damage, which add an important contribution to maintaining platelet dysfunction and promoting platelet consumption (activation, aggregation, microangiopathic hemolysis induced by severe vasospasm), resulting in thrombocytopenia. It might also be due to incomplete trophoblastic inversion of the uterine spiral arteries resulting to placental ischemia followed by release of anti-angiogenic proteins that lead to endothelial dysfunction. ${ }^{11}$ Some researcher reported that thrombocytopenia is caused due to the involvement of endothelial damage and peripheral consumption. ${ }^{12}$ It is also found that in pregnancies complicated with preeclampsia, the life span of platelet is reduced from 3 to 5 days and the altered platelet membrane accelerates its aggregation and destruction. ${ }^{13}$

Observations from our study has revealed a significant decrease in the hemoglobin level with the increase in severity of the disease (Figure 2). The anaemiais most frequently associated it is due to microangiopathic intravascular haemolysis. Normal physiological changes also affect Hematological parameters during pregnancy, and hence maternal anemia is common. ${ }^{14}$ Subbalakshmi N.K. et al, in 2014 conduct a study which show PCV, hemoglobin and platelets concentration was significantly lower in preeclampsia as compared to normal pregnancy. ${ }^{15}$ This was a retrospective study done in singleton mothers including 75 subjects with PIH. Zhang et al, have reported that the risk of anemia increases with the severity of hypertensive disorders. ${ }^{16}$ Our study also 
shows low haemoglobin and platelets level in PIH patient.

In our study the absolute lymphocyte count is decreased in preeclampsia as compared with normal pregnancy independent of the severity (Figure 2). The absolute neutrophil count is increased in preeclampsia as compared with normal pregnancy which is cause of increase in mean WBC (Figure 3). Lurie et al, 1998. ${ }^{17}$ conduct a study which shows that absolute neutrophil count was significantly elevated in preeclamptic patients and absolute lymphocyte counts declined in patients with preeclampsia as compared with uncomplicated pregnancy and increase in neutrophils count was reported in severe preeclampsia indicating an inflammatory response to the fetus or infection in the environment. The significant difference found in the $\mathrm{T}$ lymphocyte subsets in the peripheral blood of pregnant women with and without preeclampsia could be as a result of the immunosuppressive effect of placental products such as pregnancy specific beta-1 glycoprotein, progesterone or human chorionic gonadotrophin. ${ }^{18}$

On the basis of the results of our study it could be concluded that hematocrit value of preeclamptic patients was significantly higher compared to that of the normal pregnant women $(\mathrm{P}<0.05)$ (Figure 3$)$. A consequence of increased hemoconcentration is an increase in the viscosity of the blood and that has been found in preeclampsia. Plasma volume is significantly reduced and it can account in part for the increased haematocrit. ${ }^{19}$ Low plasma volume or high hematocrit especially in second and third trimester are associated with increased frequencies of fetal growth retardation, fetal death, preterm deliveries and Preeclampsia. ${ }^{20}$ Sankar Kumar Basak et al, conduct a study which show mean hematocrit value of normal pregnant, preeclamptic women were $31.94 \pm 1.2,34.88 \pm 3.03$ respectively. ${ }^{21}$ On the basis of the results of the study it could be concluded that hematocrit value of preeclamptic patients was significantly higher compared to that of the normal pregnant women $(\mathrm{P}<0.05)$.

On the basis of results of our study it concluded that mean platelets, haemoglobin, and lymphocytes counts was decrease in PIH patient while mean hematocrit and WBC increase in PIH.

\section{CONCLUSION}

PIH represents an important pathology in pregnancy, which have a grave prognosis. There was a significant decrease in the hemoglobin level with the increase in severity of the disease. Platelet count which is the main tool of early detection of thrombocytopenia in women with pregnancy induced hypertension provide the information for the early detection of thrombocytopenia in women in preventing the life-threatening complications like HELLP. High haematocrit is associated with a significantly increased risk of fetal growth retardation or preterm delivery. Therefore, present study is carried out to provide the information and suggestion to the patient and clinician for the early detection of thrombocytopenia, anemia and hemo concentration in PIH to prevent fatal complications.

\section{Funding: No funding sources}

Conflict of interest: None declared

Ethical approval: The study was approved by the Institutional Ethics Committee

\section{REFERENCES}

1. Fatemeh T, Marziyeh G, NayerehG, AnahitaG, Samira T, Maternal and perinatal outcome in nulliparious women complicated with pregnancy hypertension. J Pak Med Assoc, 2010;60(9):707-10.

2. Sultana F, Parthiban R, Shariff S. Thrombocytopenia in pregnancy induced hypertension. J Med Sci Health. 2015;1(2):19-24.

3. Report of the National High Blood Pressure Education Program Working Group on High Blood Pressure in Pregnancy. Am J Obstet Gynecol. 2000 Jul;183(1):S1-S22.

4. Cunningham FG, MacDonald PC, Gant NF: Williams Obstetrics, ed 18. Norwak, Appleton \& Lange, 1989,653-694.

5. Luft FC: Hypertensive nephrosclerosis: update. Curr. Ooin. Nephrol. Hypertension: 2004 Mar 1;13(2):14754.

6. Persu A, De Plaen JF. Recent insights in the development of organ damage caused by hypertension. Acta cardiologica. 2004 Aug 1;59(4):369-81.

7. Mushambi MC, Halligan AW. Williamson K. Recent developments in the pathophysiology and management of pre-eclampsia. Br. J Anaesthesia. 1996;76:133-48.

8. Ratnam SS, Rao KB, Arul kumaran S. Obstetrics and Gynecology for postgraduates, Vol 1. 2nd Edition. Orient Longman, Hydrabad. 1999:60.

9. Schlembach D. Pre-eclampsia. Still a disease of theories. Fukushima J Med. Sci. 2003;49(2):69-115.

10. Lescale KB, Eddlenmank KE, Cine DB. Ant platelet antibody testing in thrombocytopenic pregnant women. Am J Obs Gynecol. 1996;174(3):1014-8.

11. Karim R, Sacher RA. Thrombocytopenia in pregnancy. curr. Hematology Rep. 2004;3(2):128-33.

12. Khan A, Fahim A, Qureshi A, Nizamani GS, Azmi MA. Pregnancy Induced Hypertension; Assessment of prognostic value of platelet count in women with varying degree. Professional Med J. 2014;21(3):43640.

13. Magann EF, Martin JN Jr. Twelve steps tooptimal management of HELLP syndrome. Clin Obstet Gynecol, 1999;42(3)532-50.

14. Bora R, Sable C, Wolfson J, Boro K, Rao R. Prevalence of anemia in pregnant women and its effect on neonatal outcomes in Northeast India. The 
Journal of Maternal-Fetal \& Neonatal Medicine. 2014 Jun 1;27(9):887-91.

15. Monteiro G, Subbalakshmi NK, Pai SR. Relevance of measurement of hematological parameters in subjects with pregnancy induced hypertension. Nitte University Journal of Health Science. 2014 Mar $1 ; 4(1): 15$.

16. Zhang Q, Li Z, Ananth CV. Prevalence and risk factors for anaemia in pregnant women: a population-based prospective cohort study in China. Paediatr Perinat Epidemiol. 2009;23(4):282-91.

17. Lurie S, Frenkel E, Tuvbin Y. Comparison of the differential distribution of leukocytes in preeclampsia versus uncomplicated pregnancy. Gynecologic and obstetric investigation. 1998;45(4):229-31.

18. Onyemelukwe GC, Ekwempu CC, Alexander LC. Pregnancy-specific $\beta$-glycoprotein (SP1) in normal pregnancy in Nigeria. Intern J Gynecol Obstetr. 1985 Sep;23(4):347-9.
19. Lebel M, Grose JH, Blais R. Increased hematocritwith normal red blood cell mass in earlyborderline essential hypertension. Clin. Exp. Hypertens A. 1989;11(8):1505-14.

20. Heilmann L, Gerhold S, Tempelhoff GFV, Pollow K. The role of intravenous volume expansion inmoderate preeclampsia. Clin. Hemorheol. 2001 Jan 1;25(3, 4):83-9.

21. Sagen N, Koller O, Haram K. Haemo concentration in severe preeclampsia. Br J Obstet Gynaecol. 1982 Oct;89(10):802-5.

Cite this article as: Jhajharia N, Verma $M$. Hematological changes in pregnancy induced hypertension in their third trimester at Jhalawar Medical College, Jhalawar, India. Int J Reprod Contracept Obstet Gynecol 2019;8:3497-501. 